\section{Adriano Carlos Amorim de Paiva Sousa ${ }^{1}$ \\ Fernanda Cristina Barbosa Pereira Queiroz ${ }^{2}$ \\ Marciano Furukava \\ Jamerson Viegas Queiroz ${ }^{3}$ \\ Rudá Barros Carlos de Amorim ${ }^{4}$}

\title{
As políticas públicas para desenvolver a economia local do Rio Grande do Norte e a contribuição do turismo no litoral norte
}

\section{Resumo}

O turismo vem contribuindo de maneira significativa para o desenvolvimento social e econômico da sociedade, principalmente por se tratar de uma atividade relativamente sustentável e capaz de atingir áreas, na sua maioria, descabidas de potencial para outras atividades econômicas, em algumas praias do Rio Grande do Norte essa é a principal fonte de empregos e recursos para a população. Com a proximidade de eventos de grande visibilidade, tais como copa do mundo de futebol da FIFA e olimpíadas, existe grande especulação acerca oportunidades de negócios no setor turístico. O poder público tem papel fundamental para proporcionar a atração de investidores e garantir a infra-estrutura necessária para o desenvolvimento local. $\mathrm{O}$ estudo de caso apresenta a análise de ambiente na praia de Maracajaú, onde se avalia a implantação de empreendimentos hoteleiros, suas principais necessidades e a importância de políticas públicas que fomentem a atividade na região. A contribuição aos empreendedores e gestores que se interessem por turismo, desenvolvimento econômico e social com sustentabilidade.

Palavras chave: turismo, estratégia, economia, poder público, Maracajaú.

\section{Resumen}

El turismo viene contribuyendo de forma significante para el desarrollo social y econômico de una sociedad, principalmente por tratar-se de una actividad relactivamente sostenible y capaz de llegar en áreas, que em su mayoria, no posuien ningún outro potencial para actividades econômicas, en algunas playas del Rio Grande do Norte ese és el principal medio de emplear y captar recursos la población. Con la proximidad de eventos de grand visibilidad, así como el mundial de futbol de FIFA y las Olimpíadas, existe una grán visibilidad acerca de las oportunidades de negócios en el setor turístico. El poder público tiene um papel fundamental en buscar

\footnotetext{
1 Adriano Carlos Amorim de Paiva Sousa - Doutor em Engenharia de Produção e Serviços - Área de concentração Gestão de Negócios pela Universidade Federal de Santa Catarina - UFSC (2004). Mestre em Administração

${ }^{2}$ Fernanda Cristina Barbosa Pereira Queiroz. Doutora e Mestre em Engenharia de Produção pela Universidade Federal de Santa Catarina (2003) E-mail: fernandacbpereira@yahoo.com.br

${ }^{3}$ Jamerson Viegas Queiroz - Doutor em Engenharia de Produção e mestre em Economia pela Universidade Federal de Santa Catarina. E-mail: jvqjamerson@yahoo.com.br

${ }^{4}$ Rudá Barros Carlos de Amorim - Doutor em Engenharia de Produção e Serviços - Área de concentração - Gestão de Negócios pela Universidade Federal de Santa Catarina - UFSC (2004). Mestre em Administração
} 
investidores y garantir la infra-estructura necesaria para el desarrollo local. Este trabajo presenta una analise de ambiente en la playa de Maracajaú, donde se avalua la implantación de empreendimientos hoteleros, sus principales necesidades y la importancia de politicas publicas que incentiven a tal actividad en la región. La contribuicion de los empreendedores y gestores que se interesen por el turismo como actividad sostenible proporcionando el desarrollo economico y social.

Palavras llaves: Turismo, estratégia, economia, poder público, Maracajaú.

\section{Introdução}

A área de turismo vem ganhando importância e ampliando seus horizontes de forma acelerada no cenário nacional e internacional, pois é uma atividade com grande capacidade de geração de emprego e de renda, contribuindo significativamente para o crescimento e desenvolvimento das nações. Essa atividade envolve uma diversidade muito grande de negócios, desde aqueles relacionados diretamente ao turismo até os negócios indiretos necessários para a viabilização da atividade.

Com clima tropical, rico em belezas naturais e culturais, o Brasil atrai grande número de turistas do mundo inteiro, durante praticamente $\mathrm{o}$ ano todo. $\mathrm{O}$ aumento do número de visitantes nos últimos anos, crescimento do turismo doméstico e as perspectivas otimistas de crescimento econômico, impulsionam um crescimento acelerado do setor turístico no país, que se prepara para sediar a copa do mundo em 2014 e as Olimpíadas em 2016. De acordo com a secretaria de turismo do Rio Grande do Norte (R.N.): "Além da capital Natal, o estado tem como destinos mais visitados a cidade de
Mossoró e as praias de Pipa, Genipabu e Maracajaú".

A base da oferta existente da indústria hoteleira no Brasil é formada, ainda hoje, por hotéis de pequeno e médio porte, frequentemente de propriedade familiar (RODRIGUES, 2002). Em geral, o aumento de investimentos no setor hoteleiro está correlacionada à situação econômica do país, porém com certa defasagem. Já o crescimento da demanda, diretamente associado ao crescimento da renda, está correlacionada mais prontamente ao crescimento da economia.

As políticas públicas podem ser entendidas como o "conjunto de ações e omissões do Estado para resolver problemas que afligem a sociedade" (FONSECA, 2005), porém, em razão das demandas superarem a capacidade do Estado de responder às mesmas, se faz necessário estabelecer prioridades. Dessa forma, as políticas de turismo, que podem ser entendidas como os conjuntos de decisões em matéria turística que, integradas harmonicamente no contexto da política nacional de desenvolvimento, orientam a condução do "setor".

O presente artigo tem como objetivo analisar estrategicamente como o poder público pode fomentar a atividade turística no litoral norte do RN - Brasil. Associado ao objetivo geral traçou-se os seguintes objetivos específicos: (i) avaliar o mercado do turismo e suas perspectivas; (ii) realizar análise ambiental acerca da implantação de empreendimento hoteleiro; e (iii) sugerir ações que devam ser tomadas pelo poder público para melhorar as condições do local, visando fomentar a atividade turística.

Considerando tais proposições, norteamos nossa pesquisa com foco no seguinte questionamento: como o poder público pode fomentar a atividade turística no litoral norte do RN? Para responder à questão proposta, objetivou-se entender a estrutura do mercado turístico e suas perspectivas, além da análise 
ambiental acerca da implantação de empreendimento hoteleiro, juntamente com suas oportunidades e limitações, a fim de avaliar as principais necessidades dos empresários em relação ao poder público.

A organização do presente estudo inicia-se com essa abordagem introdutória, seguida pela seção 2, fundamentos teóricos, na qual se aborda a planejamento estratégico, políticas públicas no estado e o turismo e suas perspectivas para os próximos anos. A seção 3, metodologia, traz os procedimentos metodológicos utilizados durante $\mathrm{o}$ atual estudo. Posteriormente, a seção 4 expõe os estudos de caso realizados acerca da análise ambiental do turismo na praia de Maracajaú e as políticas públicas necessárias para fomentar a atividade no local. Em seguida, os resultados dessas análises podem ser observados na seção 5. Na seção 6, encontram-se as considerações finais do estudo, além de sugestões para possíveis trabalhos futuros e finalmente na seção 7 Referências são apresentadas as bibliografias utilizadas na pesquisa.

\section{Referencial Teórico}

\subsection{Planejamento Estratégico}

A partir do planejamento estratégico de empreendimento hoteleiro de pequeno porte na praia de Maracajaú, será avaliado o ambiente ao qual este empreendimento estaria situado, para assim, avaliar a relação do poder público com o desenvolvimento do turismo local. Nesse contexto, seu planejamento deve ter um curso de ação, os planos estratégicos podem possuir diferentes graus de formalidade, abrangência, periodicidade de preparação, e vários outros atributos.

Chiavenato (2000) propõe que "planejamento é a tarefa de traçar as linhas gerais das coisas que devem ser feitas e dos métodos de fazê-las, a fim de atingir os objetivos da empresa". Os autores Woiler e Mathias (apud LEMOS et al, 2006) destacam que o planejamento é um processo de tomada de decisões interdependentes, que procuram conduzir a empresa para uma situação futura desejada. Desta forma, o planejamento é uma das únicas ferramentas que os gestores podem utilizar para maximizar a gestão das organizações, sendo que este processo sistêmico permite a monitoração dos agentes, forças e resultados, tanto internos quanto externos.

Em geral os ambientes organizacionais estão estruturados em três níveis: geral, operacional e interno. A figura 1 ilustra os níveis e seus componentes.

De acordo com Kotler, Keller e Lane (2006), o processo de planejamento estratégico de mercado integra a gestão estratégica da organização, e contempla as seguintes etapas: missão do negócio, análise SWOT - análise do ambiente externo (oportunidades e ameaças) e Análise do ambiente interno (forças e fraquezas), estabelecimento de metas, formulação de estratégias, elaboração de programas, implementação, feedback e controle. Este trabalho irá limitar seu escopo à análise ambiental, para avaliar a relação do poder público com o desenvolvimento do turismo local.

Portanto, o planejamento estratégico do empreendimento é uma ferramenta que permite que o gestor tenha uma visão sistêmica do mercado e, permite que as tomadas de decisão sejam orientadas por um aparato de análise ambiental. 


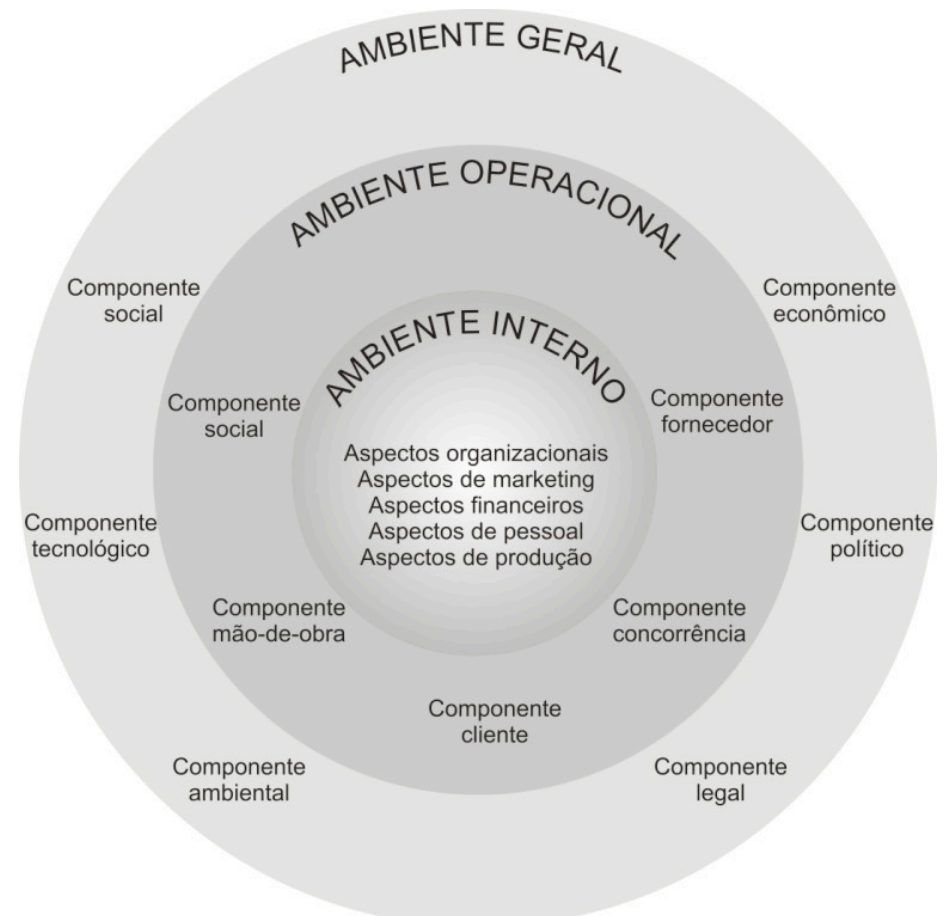

Figura 1: Níveis de ambientes na organização e seus componentes.

Fonte: Adaptado de Certo (2005)

\subsection{O turismo no $\mathrm{RN}$ e as políticas} públicas direcionadas para o setor

Segundo Cruz (2004), as regiões litorâneas, que dispõem de belas praias ensolaradas e de águas com temperaturas agradáveis (em torno de $28^{\circ} \mathrm{C}$ ), isso aliado ao clima quente, com temperatura média entre 25 e $30^{\circ} \mathrm{C}$ praticamente o ano inteiro, encontram-se os espaços mais visitados do mundo pelos turistas, as quais constituem um recurso escasso do ponto de vista do uso pela atividade. Apesar dessa escassez, os governantes e as demais autoridades responsáveis pelo planejamento de políticas públicas no Brasil, até pouco tempo atrás, não tinham despertado pra essa possibilidade de uso do nosso litoral.

A atividade turística é uma importante alternativa econômica para o litoral do nordeste brasileiro, assim, passa a fazer parte de um discurso que envolve questões voltadas principalmente à economia, tal como o desemprego, e de forma secundária a problemas sociais como a má distribuição de renda. Baseados neste discurso, diversos investimentos foram realizados pelo governo federal com o intuito de fomentar a atividade, por meio de programas de estruturação do território, como, por exemplo, a Política de Mega Projetos Turísticos e o Programa de Desenvolvimento do Turismo - PRODETUR.

De acordo com Gomes e Silva (2000), os governos estaduais nordestinos, para viabilizarem uma nova opção econômica a partir do turismo, encontraram na paisagem litorânea um grande recurso a ser explorado, de modo que essa região do Brasil foi inserida nos roteiros e pacotes turísticos passando a ser vendida como um "Novo Caribe", o "Novo Mediterrâneo", a "Nova Flórida".

O turismo ganha maior relevância como vetor de desenvolvimento para o Brasil a partir da turbulência política e da recessão econômica da década de 80 , resultado da crise do Fordismo. A grave situação socioeconômica, com altas taxas de desemprego, foi a justificativa para que nos anos de 1990, a Empresa Brasileira de Turismo - EMBRATUR elaborasse uma política pública federal específica para o turismo, a Política Nacional de Turismo - 
PNT, que tinha como propósito alcançar alguns resultados, tais como (FONSECA, 2005):

- Melhoria da qualidade de vida da população de cidades litorâneas, com grande potencial turístico;

- Diversificação qualitativa dos bens e serviços produzidos e da infra-estrutura receptiva do turismo nacional;

- Geração de novos empregos e a manutenção dos já existentes;

- Qualificação e requalificação dos recursos humanos;

- Aproveitamento da mão de obra não qualificada e sua conseqüente capacitação;

- Redução das desigualdades regionais;

- Proteção ao meio ambiente e ao patrimônio histórico e cultural;

- Integração socioeconômica e cultural da população;

- Inserção do Brasil no cenário internacional, construindo uma imagem externa positiva.
O PRODETUR/NE foi financiado com recursos do BID e teve no Banco do Nordeste o seu órgão executor. Segundo Fonseca (2005), no PRODETUR/NE, foram investidos cerca de US\$ 670 milhões, distribuídos nos seguintes componentes: aeroportos (34\%), saneamento básico (24\%), transportes $(12 \%)$, recuperação do patrimônio histórico $(5 \%)$, desenvolvimento institucional (4\%), preservação e proteção ambiental (3\%) e outros (18\%). Ainda de acordo com o autor, o Rio Grande do Norte, recebeu uma parcela de $9 \%$ desses recursos.

Os municípios selecionados pelo governo do Estado para fazer parte do PRODETUR/ RN foram: Ceará-Mirim, Extremoz, Natal, Parnamirim, Nísia Floresta e Tibau do Sul, localizados no litoral oriental. Fonseca (2005). O quadro seguinte aponta a distribuição dos recursos no $\mathrm{RN}$ :

\begin{tabular}{|c|c|c|c|c|c|c|}
\hline \multirow[t]{2}{*}{ Localidade } & \multirow{2}{*}{$\begin{array}{l}\text { Desenvolvimento } \\
\text { Institucional }\end{array}$} & \multicolumn{3}{|c|}{ Obras Múltiplas } & \multirow{2}{*}{ Total } & \multirow{2}{*}{$\%$} \\
\hline & & Estradas & $\begin{array}{c}\text { Recuperação } \\
\text { Ambiental }\end{array}$ & Saneamento & & \\
\hline Natal & - & $3.254 .296,86$ & $1.529 .788,11$ & $8.403 .582,40$ & $13.187 .667,37$ & 23,10 \\
\hline Nísia Floresta & $297.441,60$ & $3.830 .966,89$ & - & - & $4.128 .408,49$ & 7,23 \\
\hline Parnamirim & $297.441,60$ & $2.556 .488,89$ & - & - & $2.853 .930,49$ & 5,00 \\
\hline Ceará-Mirim & $297.959,50$ & $1.455 .563,20$ & - & - & $1.753 .522,70$ & 3,07 \\
\hline Tibau do Sul & $297.676,80$ & $744.999,87$ & - & - & $1.042 .676,67$ & 1,82 \\
\hline Extremoz & $297.366,80$ & $618.763,54$ & - & - & $916.130,34$ & 1,60 \\
\hline Estado do $\mathrm{RN}^{*}$ & $1.223 .810,23$ & - & - & - & $1.223 .810,23$ & 2,14 \\
\hline Subtotal & $2.711 .696,53$ & $12.461 .079,25$ & $1.529 .788,11$ & $8.403 .582,40$ & $25.106 .146,29$ & 43,98 \\
\hline Aeroporto & \multicolumn{5}{|c|}{$31.966 .458,20$} & 56,01 \\
\hline Total Geral & \multicolumn{5}{|c|}{$57.072 .604,49$} & 99,99 \\
\hline
\end{tabular}

Tabela 1: Investimentos realizados pelo PRODETUR no Rio Grande do Norte (Brasil) Fonte: FONSECA (2005)

Afinal, é possível diagnosticar que as políticas públicas, deixaram de lado o litoral Norte do estado, em especial a praia de Maracajaú, que é um dos destinos mais visitados por turistas, tendo concentrando os investimentos em Natal e litoral Sul. Diante dessa situação, é de grande importância a atuação do poder público na região, com 
políticas voltadas para as principais necessidades, que serão apontadas nas próximas páginas deste trabalho.

O próximo capítulo caracteriza o método que a pesquisa segue para buscar cumprir seus objetivos, relacionando as fontes de pesquisa e as principais instituições que dispõem de dados e informações acerca de turismo no estado do Rio Grande do Norte e as políticas públicas direcionadas para a atividade econômica no local.

\section{Procedimentos Metodológicos}

\subsection{Caracterização do Método da} Pesquisa

O presente trabalho é caracterizado, de acordo com a Metodologia Científica, como uma pesquisa qualitativa e quantitativa. $\mathrm{O}$ estudo se fundamenta primeiro numa análise quantitativa para avaliar aspectos

como: desempenho do turismo, taxa de ocupação dos leitos, desembarque de passageiros, visitantes a praia, entre outros dados que ilustrem a situação e perspectivas do turismo no estado do Rio Grande do Norte.

Em relação aos procedimentos utilizados, classifica-se como uma pesquisa básica, um estudo de múltiplos casos, com intuito de obter informações relacionadas ao turismo e as políticas públicas direcionadas para o setor, no litoral norte do RN.

\subsection{Universo e Amostra}

O universo desta pesquisa é formado por empreendimentos turísticos localizados na praia de Maracajaú, o fluxo turístico no estado e a revisão acerca de políticas públicas que contemplam o litoral norte do Rio Grande do Norte. A amostra selecionada para realizar esta pesquisa consiste na análise dos principais empreendimentos hoteleiros do local.

\subsection{Procedimento de Pesquisa}

$\mathrm{O}$ procedimento de pesquisa desse trabalho iniciou-se com uma revisão bibliográfica em literatura especializada, buscando dados e informações nos principais institutos de pesquisa do Brasil, artigos publicados em anais de congressos, livros, dissertações e teses. Esta etapa do trabalho teve como principal objetivo o levantamento de informações sobre conceitos sobre o turismo no $\mathrm{RN}$, a evolução desse setor e as políticas públicas do governo, conceitos sobre estratégia, análise de ambiente e perspectivas.

A pesquisa está direcionada para desenvolver o planejamento estratégico de um empreendimento hoteleiro de pequeno porte, assim, será avaliado o contexto ambiental e estabelecidas as diretrizes estratégicas do negócio. Além de estratégia e turismo, o referencial teórico disserta acerca das políticas públicas destinadas ao local.

A fim de realizar os objetivos propostos, o trabalho será concluído, apresentando-se uma série de medidas que devem ser contempladas pelas políticas públicas, a fim de fomentar o turismo na região.

Os aspectos metodológicos de análise do tema concentram-se na busca de informações em diversas fontes, tais como: (1) dados coletados a partir de revisão bibliográfica na literatura especializada, que inclui: artigos, relatórios de pesquisas, matérias jornalísticas publicadas em revistas e jornais, anuários que tratam dos mecanismos de financiamento voltados para o setor do turismo, especificamente no ramo da hotelaria; além de publicações do governo federal e estadual acerca do turismo e suas perspectivas, principalmente no RN; (2) Consultas a sites de empreendimentos turísticos, institutos de pesquisas e agências nacionais e regionais. Anuários e indicadores do governo federal, acerca do turismo no país. Ministério do Turismo do Brasil, EMBRATUR, Secretaria de Turismo do RN (SETUR-RN), EMPROTUR, IBGE, INFRAERO, que são 
instituições que contêm os principais dados e informações do turismo no Brasil.

4. Estudo de caso - Planejamento estratégico de empreendimento hoteleiro na praia de Maracajaú/RN

\subsection{Introdução}

Há uma forma melhor de se pensar no futuro. Planejar é a palavra apropriada para se projetar um conjunto de ações para atingir um resultado. Uma organização pode obter vários benefícios praticando de forma correta a administração estratégica. Talvez o mais importante seja a tendência de tais organizações aumentarem seus níveis de lucro.

\subsection{Análise do ambiente}

As informações coletadas nesta etapa serão usadas posteriormente, na definição da diretriz estratégica do empreendimento. Este processo de monitoramento do ambiente organizacional é primordial para que sejam identificadas as oportunidades e riscos, atuais e futuros que podem vir a influenciar a capacidade da empresa de atingir suas metas; nesse contexto, o ambiente organizacional engloba o conjunto de fatores internos e externos.

\subsubsection{Ambiente geral}

O ambiente geral está a um nível externo a organização, formado por componentes que têm amplo escopo e sobre o qual a organização não exerce controle, estes componentes são destacados a seguir:

\subsubsection{Componente econômico}

$\mathrm{O}$ índice de visitação turística no Rio Grande do Norte em 2010 cresceu 12,43\% em relação a 2009. A Secretaria de Estado do Turismo calcula que uma média de 2,6 milhões de turistas visitou o Estado em 2010. Deste total, $7 \%$ são visitantes provenientes de outros países.

No aeroporto de Natal, em cinco anos, de 2006 a 2010, o número total de desembarques teve um crescimento acima de $80 \%$, como é possível constatar na tabela a seguir:

\begin{tabular}{|c|c|c|c|c|c|c|c|}
\hline \multirow{2}{*}{ Ano } & \multicolumn{2}{|c|}{ Regular } & \multicolumn{3}{|c|}{ Não Regular } & \multirow{2}{*}{ Total } & \multirow{2}{*}{$\begin{array}{c}\text { Var. \% } \\
\text { Anual }\end{array}$} \\
\cline { 2 - 7 } & Doméstico & Internacional & Doméstico & Internacional & Executiva/Geral & & Anual \\
\hline $\mathbf{2 0 0 6}$ & 944.462 & 72.749 & 194.686 & 176.412 & 3.647 & 1.391 .956 & - \\
\hline $\mathbf{2 0 0 7}$ & 1.198 .588 & 81.496 & 158.019 & 137.261 & 2.801 & 1.578 .165 & 13.38 \\
\hline $\mathbf{2 0 0 8}$ & 1.324 .527 & 79.605 & 151.477 & 84.439 & 3.321 & 1.643 .369 & 4.13 \\
\hline $\mathbf{2 0 0 9}$ & 1.643 .825 & 77.376 & 120.443 & 50.266 & 2.203 & 1.894 .113 & 15,26 \\
\hline $\mathbf{2 0 1 0}$ & 2.174 .432 & 86.505 & 121.094 & 31.328 & 2.474 & 2.415 .833 & 27,54 \\
\hline
\end{tabular}

Tabela 2: Movimento operacional - aeroporto Augusto Severo

Para entendermos o ambiente econômico do setor acerca do qual o estudo se desenvolve, inicialmente serão expostos dados do produto interno bruto (PIB) do estado do
Rio Grande do Norte, este indicador aponta o grau de desenvolvimento econômico, de Natal a capital do estado e, do município onde o empreendimento deverá ser implantado.

\begin{tabular}{|l|r|r|}
\hline \multicolumn{3}{|c|}{ Dados da região } \\
\hline Local & PIB & PIB per capita \\
\hline Rio Grande do Norte & $\mathrm{R} \$ 25.481 .000,00$ & $\mathrm{R} \$ 8.203,00$ \\
\hline Natal & $\mathrm{R} \$ 8.656 .932,00$ & $\mathrm{R} \$ 10.847,40$ \\
\hline Maxaranguape & $\mathrm{R} \$ 41.275,00$ & $\mathrm{R} \$ 4.461,66$ \\
\hline
\end{tabular}

Tabela 3: Produto interno bruto (PIB) da região

Fonte IBGE (2008) 
O comparativo do PIB na tabela acima apresenta o município de Maxaranguape com um valor per capita bem abaixo da média quando comparado com a média do país, da capital e do estado, mostrando que o município apresenta um baixo grau de desenvolvimento econômico. Diante dessa informação, é essencial compreender a natureza das atividades econômicas geradoras do PIB:

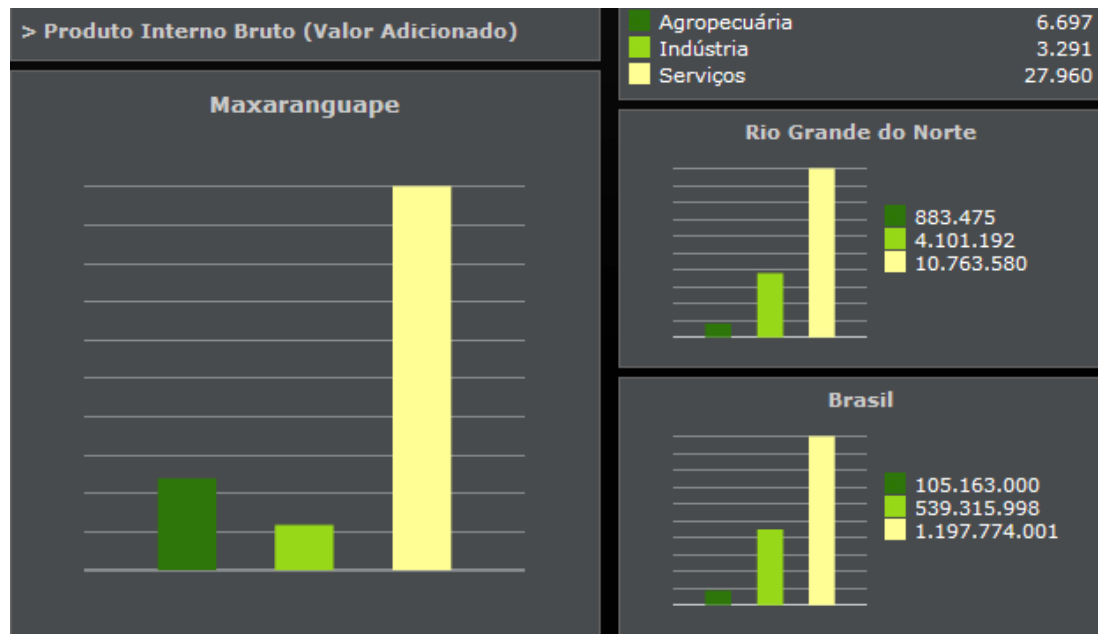

Gráfico 1: Caracterização do PIB.

Fonte: IBGE (2008)

A partir do gráfico é possível perceber que no município onde o empreendimento deverá ser implantado, assim como no estado e no país, os serviços compõem a maior parcela de recursos que compõem o PIB, entretanto, percebe-se em particular uma participação bem pequena da indústria no local.

\subsubsection{Componente social}

Este tópico trata da compreensão das características da sociedade na qual o empreendimento estará situado e do público alvo, num primeiro momento, serão apresentados dados em relação à educação no município, mostrados na tabela abaixo, num comparativo com o estado e o país:

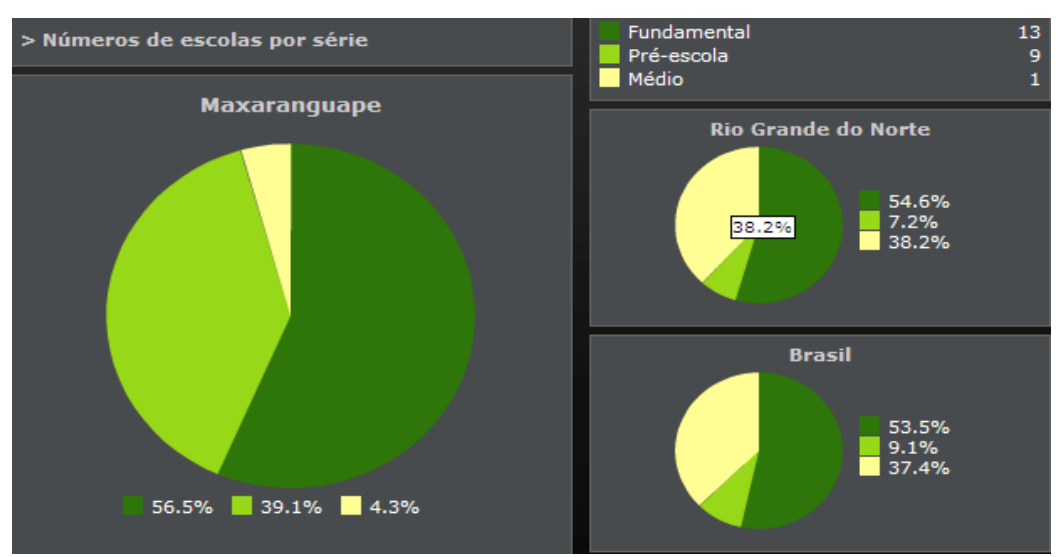

Gráfico 2: Número de escolas por série.

Fonte: INEP, Censo Educacional (2009) 
O gráfico apresenta dados curiosos, quando se compara o município com o estado e o país, é possível perceber que a educação local contempla basicamente o ensino básico e que o ensino médio está bastante defasado quando no comparativo apresenta uma taxa pouco acima de 4\%, enquanto o estado apresenta valores acima de 37\%; esses valores podem dimensionar o nível da formação da mão de obra local.
Outro aspecto importante para entender as condições que a população vive é a forma como saúde é tratada no local, de que maneira as instituições se comportam, o gráfico abaixo oferece alguns dados importantes acerca do assunto no município, mantendo a comparação já apresentada em outros gráficos acima:

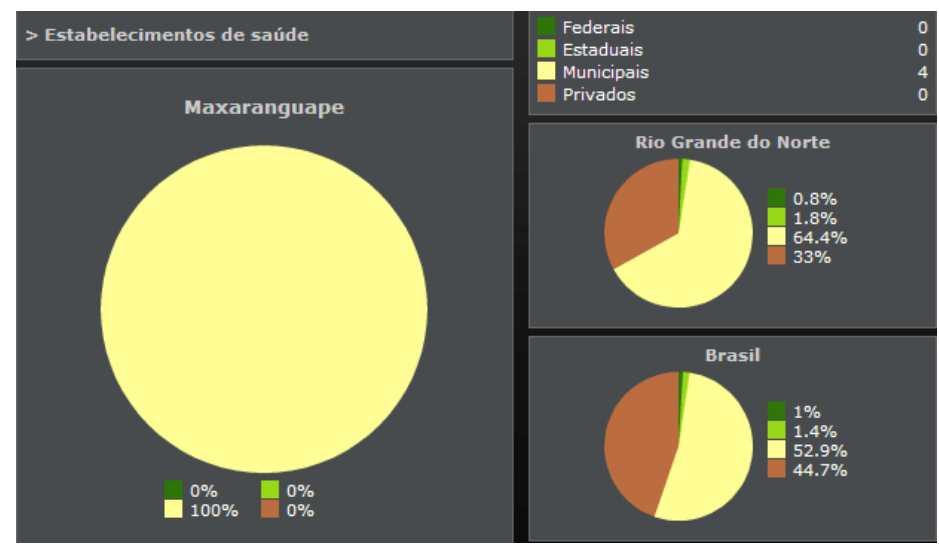

Gráfico 3: Estabelecimentos de saúde. Fonte: DATASUS (2009)

Um dado curioso pode ser percebido no gráfico: no município de Maxaranguape existem apenas instituições municipais de saúde, não havendo nenhuma instituição a nível federal, municipal ou mesmo privada.

De acordo com o portal da transparência do governo federal, em 2010 foi repassado ao município de Maxaranguape à quantia de $\mathrm{R} \$$ 10.354.982,05; dos quais apenas $\mathrm{R} \$$ 20.000,00 foi destinado à estruturação da rede de serviços de atenção básica de saúde, ou seja, menos de $2 \%$ da verba total.

\subsubsection{Componente político}

É essencial a participação da iniciativa pública para fortalecer o destino turístico praia de Maracajaú, de acordo com o portal da transparência, o governo federal destinou mais de dez milhões no ano de 2010 para o município de Maxaranguape, nesse montante não existe nenhuma cota destinada especificamente ao desenvolvimento do turismo no local.

\subsubsection{Componente legal}

É necessário contratar um contador profissional para legalizar a empresa nos seguintes órgãos: junta comercial, secretaria da receita federal (CNPJ), secretaria estadual de fazenda, prefeitura do município para obter o alvará de funcionamento, cadastramento junto à caixa econômica federal no sistema "Conectividade Social INSS/FGTS”, corpo de bombeiros militar.

\subsubsection{Componente ambiental}

Na praia de Maracajaú, existe uma área de proteção ambiental (APA) dos recifes de corais, que visa a preservação da pesca e exploração do turismo submarino naquela 
região litorânea. Dados de pesquisas (tabela 4) mostram que a visita aos parrachos para realização de mergulho é o principal motivo da visita dos turistas a praia, que possui outra diversidade de belezas naturais como dunas e lagoas que podem promover mais opções de lazer para que os turistas pernoitem no local. Apesar do apelo ecológico, o local não conta com coleta de lixo frequente ou mesmo possui saneamento básico.

\subsubsection{Ambiente operacional}

\subsubsection{Componente cliente}

A interpretação dos dados desse componente pode ajudar a organização a se posicionar de maneira adequada diante do mercado consumidor. A partir de dados que foram apresentados anteriormente, podemos concluir que: $88,26 \%$ dos turistas que visitam o estado são nacionais (tabela 3) e a praia de Maracajaú está entre os cinco destinos preferidos por eles, no estado. A tabela abaixo mostra os principais motivos da visita dos turistas ao local.

\begin{tabular}{l|c|c}
\hline \multicolumn{1}{c|}{ Motivos } & $f$ & $\%$ \\
\hline 1 - Mergulho & 82 & 33,8 \\
\hline 2 - Indicação de terceiros & 42 & 17,2 \\
\hline 3 - Corais/Parracho & 27 & 11,1 \\
\hline $4-$ Beleza natural & 25 & 10,2 \\
\hline $5-$ Conhecer/curiosidade & 15 & 6,1 \\
\hline 6 - Material publicitário & 11 & 4,5 \\
\hline 7 - Turismo & 6 & 2,5 \\
\hline $8-$ Pacote & 6 & 2,5 \\
\hline $9-$ Peixes & 5 & 2,0 \\
\hline $10-$ Praia & 5 & 2,0 \\
\hline $11-$ Piscinas naturais/ambiente & 5 & 2,0 \\
\hline marinho & 15 & 6,1 \\
\hline \multicolumn{1}{c|}{ Total } & 244 & 100,0 \\
\hline
\end{tabular}

Tabela 4: Motivos da visita ao local. Fonte: SILVA (2009, p.62)

A tabela apresenta que os turistas visitam a praia por suas atrações naturais, principalmente o mergulho aos parrachos. A nível comportamental é possível avaliar o perfil sócio-demográfico das pessoas que visitam o local, apresentado na tabela abaixo, em pesquisa realizada na própria praia no ano de 2008:

\begin{tabular}{|c|c|c|c|}
\hline \multirow{6}{*}{ Renda Familiar } & Até R\$ 2.000 & 21 & 10,4 \\
\hline & Até R\$ 2.001 e 4.000 & 34 & 16,8 \\
\hline & Até R\$ 4.001 e 6.000 & 38 & 18,8 \\
\hline & Até R\$ 6.001 e 8.000 & 31 & 15,3 \\
\hline & Até RS 8.001 e 10.000 & 24 & 11,9 \\
\hline & Acima de 10.000 & 54 & 26.7 \\
\hline Total & & 202 & 100,0 \\
\hline \multirow{6}{*}{ Profissão/Ocupação } & Profissional liberal & 76 & 33,9 \\
\hline & Funcionário público & 41 & 18,3 \\
\hline & Autônomo & 20 & 8,9 \\
\hline & Aposentado/pensionista & 3 & 1,3 \\
\hline & Estudante & 47 & 21,0 \\
\hline & Outra & 37 & 16.5 \\
\hline Total & & 224 & 100,0 \\
\hline \multirow{6}{*}{ Nivel Educacional } & Superior completo & 137 & 60,4 \\
\hline & Superior incompleto & 44 & $19,4 \%$ \\
\hline & Médio completo & 9 & 4,0 \\
\hline & Médio incompleto & 23 & 10,1 \\
\hline & Fundamental completo & 9 & 4,0 \\
\hline & Fundamental incompleto & 5 & 2.2 \\
\hline \multicolumn{2}{|l|}{ Total } & 227 & 100,0 \\
\hline
\end{tabular}

Tabela 5: Características sócio-demográficas dos turistas.

Fonte: SILVA (2009, p.56) 
Importante destacar que 26,7\% dos entrevistados apresentam renda superior a $\mathrm{R} \$ 10.000,00$ e $34,6 \%$ que apresentam renda entre R\$ 2.000,00 e R\$ 6.000,00; esses dados apresentam que os turistas que visitam o local têm considerável poder aquisitivo. Vale observar ainda que mais de $30 \%$ do público é profissional liberal, seguido por $21 \%$ que são estudantes. A respeito do nível educacional, $60 \%$ dos entrevistados possuem nível superior completo, mostrando que a maioria dos turistas possui bom grau de instrução.

\section{Resultados Obtidos}

O objetivo foi respondido na medida em que foi possível propor uma série de ações que devem ser direcionadas para diversas áreas, de forma a contribuir para o desenvolvimento do turismo no local, que é a principal atividade econômica do local, o problema foi solucionado apontando tais sugestões descritas abaixo.

É uma realidade brasileira que as demandas da população crescem em ritmo mais acelerado do que o poder público tem capacidade de atender, porém o que torna o caso específico do local estudado mais interessante é o fato de a praia de Maracajaú, que, de acordo com a secretaria de turismo do estado do Rio Grande do Norte, a praia está entre os cinco destinos mais procurados no estado, se trata da principal fonte geradora de emprego e renda do local, sendo agente propulsor econômico e social.

Para avaliar as políticas públicas propriamente ditas, vamos realizar a análise em dois níveis: externo e interno, que são respectivamente, políticas gerais para desenvolver a atividade e políticas específicas para o local onde será estabelecido o negócio.

Em relação às políticas externas, é possível relacionar as seguintes necessidades dos empresários:
- Falta de incentivo financeiro: existe a necessidade de crédito facilitado para pequenas e micro empresas, redução de alíquotas e isenções fiscais são essenciais para incentivar os empresários.

- Divulgação do destino turístico: para aumentar o número de visitantes, com políticas específicas para o fator sazonalidade.

Em relação às políticas internas, aquelas que devem ser voltadas para o município em questão, onde o empreendimento será localizado, é possível relacionar as seguintes necessidades:

- Qualificação da mão-de-obra local, como pode ser percebido no estudo de caso, 95\% dos equipamentos de educação do município são voltados para pré-escola e ensino fundamental, sendo a mão-de-obra local, carente de treinamentos para atender bem o turista.

- Estabelecimentos de saúde, conforme apresentado no estudo de caso, o município é carente de instituições de saúde, o que é essencial para que o destino turístico esteja capacitado a receber pessoas de diversas partes do mundo, quanto para os próprios moradores e funcionários do empreendimento.

- Segurança pública, um fator essencial para que os turistas sintam-se a vontade durante sua estadia, atualmente a presença da polícia na praia não é constante e o risco é um fator que contribui negativamente para a imagem local.

- Preservação do meio ambiente e saneamento básico, é possível perceber à contradição de um destino turístico que oferece belezas naturais e tem nelas a causa principal da visita dos turistas ao local, onde há uma área de preservação ambiental, porém não possui saneamento básico na maioria das casas, 
além de não existir coleta seletiva e lixo freqüente no local.

Afinal, é possível perceber que, sem o apoio de políticas públicas como as listadas acima, voltadas para o desenvolvimento estrutural e social, o poder econômico local fica limitado, torna-se difícil a atração de novos empreendedores. Uma vez realizados os investimentos nas áreas propostas, o empreendedor encontra um ambiente favorável à instalação de novos estabelecimentos de turismo. Investimento significa desenvolvimento da economia e sociedade local, aumentando a qualidade de vida da população.

\section{Considerações Finais}

Quando uma pesquisa tem início, na maioria das vezes não se tem a real idéia de onde será possível chegar. No presente trabalho, as expectativas acerca do assunto estudado superaram as expectativas do autor, no sentido de conseguir abranger resultados e informações que antes não se imaginava que seriam reunidas nestas páginas.

A revisão bibliográfica se fundamentou em três assuntos chave: turismo, poder público e planejamento estratégico. Em tese, a relação desses assuntos foi tratada da seguinte forma: apresentado o cenário turístico do Rio Grande do Norte e suas perspectivas, diante de algumas informações acerca deste ambiente, são mensuradas as ações tomadas pelo poder público para fomentar a atividade no Nordeste, desde a sua inclusão nos planos do governo federal, para desenvolver esta região economicamente desprovida de indústrias e onde o turismo é a fonte geradora de emprego e renda, responsável pelo desenvolvimento econômico daquela região. $\mathrm{O}$ estudo de caso vem para fazer o link entre mercado, empresários e gestores, permitindo sua visão ao cenário real do ambiente competitivo ao qual estaria imerso o empreendimento, caracterizado por suas necessidades em relação ao poder público, que fora o objetivo principal do trabalho.

\section{Referências Bibliográficas}

CERTO, S.C. Administração Moderna. 9a edição, São Paulo:Prentice, 2005.

CHIAVENATO, I. Introdução à Teoria Geral da Administração. Rio de Janeiro: Campus, 2000.

CRUZ, R. C. Políticas de turismo e território. São Paulo: Contexto, 2004.

DATASUS. Indicadores e Dados Básicos Brasil. 2009 - Disponível em:

$<$ http://tabnet.datasus.gov.br/cgi/idb2009/novidades.htm>. Acesso em: 25 jun. 2006.

FONSECA, M. A. P. Espaço, políticas de turismo e competitividade. Natal, RN: EDUFURNEditora da UFRN, 2005.

GOMES e SILVA. Turismo, inovações e crescimento econômico local. Scripta Nova: Revista Electrónica de Geografía y Ciencias Sociales. Universidad deBarcelona. No 69 (56), 1 de agosto de 2000.

IBGE (Instituto Brasileiro de Geografia e Estatística). A Síntese dos Indicadores Sociais 2008:Uma Análise das Condições de Vida da População Brasileira. 2008. Disponível em: $<$ http://www.ibge.gov.br/home/presidencia/noticias/noticia_visualiza.php?id_noticia=1233\&>. Acesso em 10 mai. 2004. 
INEP (Instituto Nacional de Estudos e Pesquisas Educacionais Anísio Teixeira). Censo Educacional 2009. Disponível em: <http://educarparacrescer.abril.com.br/indicadores/censoescolar-2009-mudancas-educacao-517168.shtml> Acesso em: 15/04/2006.

KOTLER, P. Administração de marketing: análise, planejamento, implementação e controle.

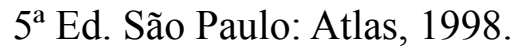

KOTLER; KELlER e LANE. Administração de Marketing: A Bíblia do Marketing. Prentice Hall Brasil, $12^{\mathrm{a}}$ edição, 2006.

LEITÃO, D. M. Administração estratégica: abordagem conceitual e atitudinal. Rio de Janeiro: SENAI/DN, Petrobras, 1996.

LEMOS, A.C.F.V. et al. O planejamento Estratégico como ferramenta competitiva. VII SEMEAD, São Paulo, 2006.

PLANO CORES DO BRASIL. Publicação do Ministério do turismo, 2005.

PORTER, M. E. Competitive Advantage: Creating and Sustaining Superior Performance. New York: Free Press, 1985.

RODRIGUES, R.M. Histórico de desenvolvimento de hotéis no Brasil. Hotel Investment Advisors (HIA), mar. 2002 (site institucional).

SETUR-RN, 2010. Disponível em: <www.brasil-natal.com.br> Acesso em: 20 abr. 2010.

SILVA, C. B. Análise da atividade turística desenvolvida na área de proteção ambiental dos recifes de corais - RN. Dissertação de Mestrado apresentada ao Progra de Pós-graduação em Desenvolvimento e Meio Ambiente (PRODEMA) - Universidade Federal do Rio Grande do Norte. Disponível em: <http://bdtd.bczm.ufrn.br/tedesimplificado/tde_arquivos/29/ TDE-2009-06-10T052125Z2027/Publico/ClebiaBS.pdf>. Acesso em: 03 abr. 2006. 